\title{
Hunter Disease: A Case Report
}

\author{
Bajaj N ${ }^{1}$ Joshi P ${ }^{2}$ Bajaj SK ${ }^{3}$ \\ ${ }^{1}$ Dr. Nandita Bajaj, Consultant Pediatrician, Siddhartha Hospital, Balaju, Kathmandu. ${ }^{2}$ Dr. Prakash Joshi, Pediatric \\ Resident, National Academy of Mediacal Sciences, Bir Hospital,Kathmandu. ${ }^{3}$ Dr. Satish Bajaj, Consultant Radiologist, \\ Siddhartha Hospital, Balaju, Kathmandu, Nepal.
}

Address for Correspondence: Dr. Prakash Joshi. E-mail: prakashdrjoshi@yahoo.com

\begin{abstract}
Mucopolysaccharidosis type II (MPS II; Hunter syndrome) is a rare X-linked recessive disease caused by deficiency of the lysosomal enzyme iduronate-2-sulphatase, leading to progressive accumulation of glycosaminoglycans in nearly all cell types, tissues and organs ${ }^{1}$. Common presenting features include facial dysmorphism, organomegaly, joint stiffness and contractures, pulmonary dysfunction, myocardial enlargement and valvular dysfunction, and neurologic involvement ${ }^{2}$. Until recently, there has been no effective therapy for MPS II, and care has been palliative. Enzyme replacement therapy (ERT) with recombinant human iduronate-2-sulphatase (idursulfase), however, has now been introduced ${ }^{1}$. Here we present a boy who was brought to medical attention at the age of 12 yrs for short stature. The purpose of presenting this case is to highlight the distinctive manifestations of Hunter syndrome by which it can be clinically differentiated from the more common and similar syndrome of Hurler's Disease.
\end{abstract}

\section{Case}

A 12 years old boy from Dumkibas, Nawalparasi born as the third child to a healthy non-consanguineously married couple was brought with the complaint of delay in onset of speech and regression of acquired speech noticed since the age of four years. As other mile stones till the age of four years were normal, not much attention was paid to the delay in speech. Though, at the beginning the child used to say a few bi-syllabic words, regression of speech started gradually and is now reduced to incomprehensible shrill cry. Meanwhile progressive coarsening of facial features was noticed and became gross by six year of age. Subsequently delay in growth of whole body was noticed which was associated with gradual stiffening of all the limbs. Though there was history of subnormal intelligence, the child used to play with his peer group and recognize parents well. The elder brother and sister have normal physical and mental health.

On examination the child was found to have short stature with subnormal intelligence making incomprehensible sounds. He had coarse facies with depressed broad flat nose, large thick ears, thick lips and large protruding tongue. Anthropometry showed that the head was large with OFC of $53 \mathrm{~cm}$. Height for age was $105 \mathrm{~cm}$ lying below $5^{\text {th }}$ centile with $Z$ score -6.9 Weight for age was $21 \mathrm{Kg}$ lying below $5^{\text {th }}$ centile with $Z$ score -3.8 and weight for height was above $95^{\text {th }}$ centile suggesting severe stunting, severely undernourished but not wasted. Upper segment lower segment ratio was 1.05 which lies within normal limit for the age. Arm span was shorter than height by $8 \mathrm{~cm}$ suggesting short limbs. Abdominal examination revealed a protuberant abdomen with umbilical hernia. There was marked lordosis without gibbus. MRI Head revealed Cerebral atrophy with hydrocephalus (Foramen Monroe level).

Ophthalmic examination was normal. Semi quantitative spot test for urinary GAG excretion was positive. On the basis of presentation, clinical evaluation and radiological findings as well as positive urinary GAG excretion diagnosis of Hunter was made however enzyme assay, iduronate-2-sulfatase (I2S) activity, is required for further confirmation. The parents could not afford the confirmation test. 

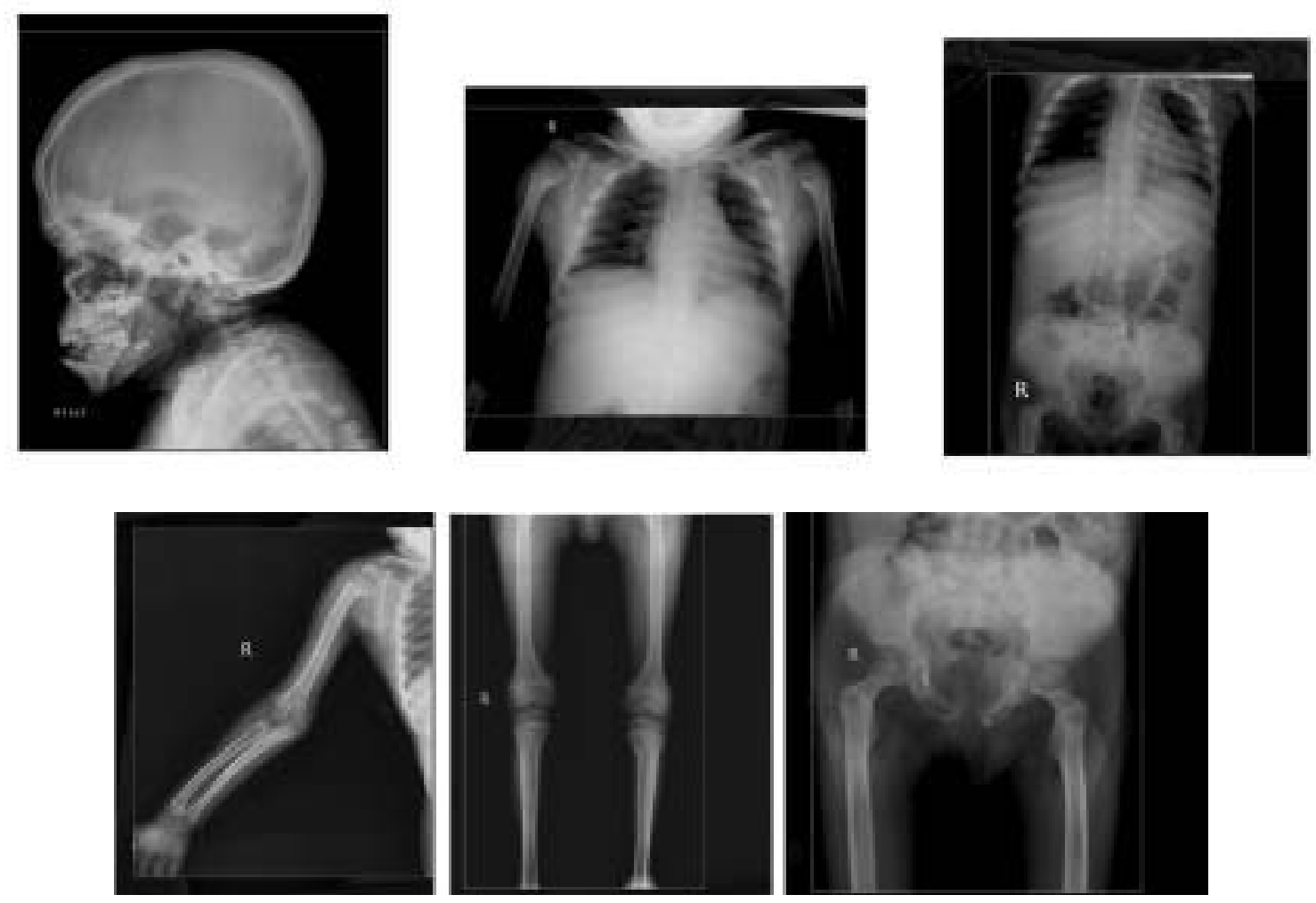

X-rays showing features of Dysostosis Multiplex in this patient.

1. Skull: Thick Calveria with Craniosynostosis and $\mathrm{J}$ shaped Sella.

2. Mandible: Short and deformed Ramii.

3. Ribs: Short and anterior widening.

4. Shoulder Joints: Deformed Glenoid Cavity.

5. Elbow Joint: Osteopenia with deformed proximal Ulnar and Radial head.

6. Wrist Joint: Dysplasia with Bachydactaly.

7. Spine: Flattening with short segment and Kyphosis at Thoracolumbar region.

8. Hip Joint: Widened, Flattened Acetabulum with Coax vera.

9. Femur and Tibia: Osteopenic bone with thinned out cortices with Metaphyseal flaring at knee joint.

\section{Discussion}

The first description of an MPS disease was made by Charles Hunter, a Canadian physician who, in 1917 , described a rare disease in two brothers ${ }^{1,2}$. Mucopolysaccharidosis are hereditary progressive diseasecausedbymutations ofgenes coding forlysosomal enzymes needed to degrade Glycosamineglycan (acid mucopolysaccharides ) which is a long chain complex charbohydrate and a major constituent of the ground glass substance of connective tissue, as well as nuclear and cell membrane ${ }^{3}$. In affected patients, undegraded or partially degraded GAG accumulates within lysosomes and is excreted in excess in the urine $e^{2,4}$. It is the accumulation, or storage, of GAG within lysosomes that contributes to the signs and symptoms of these disorders ${ }^{2}$.

Among the different types of MPS the above mentioned features are present in Hurler and Hunter Syndrome. However skeletal and mental defect are milder, disease process is slower, dysostosis multiplex is milder, corneal clouding is absent and patients usually do not have gibbus deformity in Hurler Syndrome as compared to Hunter Syndrome ${ }^{3}$.

Mucopolysaccharidosis II, also known as Hunter syndrome, is a rare, X-linked disorder caused by a deficiency of the lysosomal enzyme iduronate-2sulfatase $^{1,2,3,5}$. As MPS II is an X-linked recessive condition, it would not be expected to affect females. Despite this, a few girls have been reported with MPS II ${ }^{1,3}$. Phenotypic expression in females may be the result of structural abnormalities of the $\mathrm{X}$ chromosome, homozygosity for disease-causing mutations, or preferential X chromosome inactivation ${ }^{4,5}$.

It is estimated that one in every 25,000 babies born in the United States will have some form of the mucopolysaccharidoses ${ }^{6}$. Hunter syndrome, or MPS II, is 1 of the most common MPSs, with an estimated prevalence of 1 in 170000 male live births ${ }^{2}$.

Hunter syndrome is a disease with multiorgan and multisystem involvement that has a variable age 
of onset and a variable rate of progression ${ }^{2}$. Patients with the disease present with a wide clinical spectrum, ranging from mild to severe form ${ }^{1,3,7}$. The traditional classification of patients into 'mild'(Type IIB) or 'severe'(Type IIA) subtypes, on the basis of length of survival and the presence or absence of CNS disease, is a gross simplification ${ }^{1,6}$. The disorder should rather be regarded as a continuum between two extremes ${ }^{1}$.

Patients typically appear normal at birth in both the types. ${ }^{2}$ In its severe form, clinical features appear between 2 and 4 years of age. ${ }^{2,6}$ In these cases, progressive neurologic involvement is prominent and progresses to severe mental impairment. ${ }^{2}$ Developmental decline is usually noticed between the ages of 18 and 36 months, followed by progressive loss of skills ${ }^{6}$ Death usually occurs in the first or second decade of life, usually because of obstructive airway disease and/or cardiac failure ${ }^{2,6}$. At the opposite end of the spectrum, physical characteristics of MPS II B are less obvious and progress at a much slower rate ${ }^{2,6}$. Diagnosis is often made in the second decade of life. ${ }^{6}$ These patients have minimal neurologic dysfunction with normal intelligence, near normal stature and survive into adulthood. Death occurs usually by cardiac failure in fourth decades of life $\mathrm{e}^{2,6,7}$.

The appearance and skeletal abnormalities are similar regardless of the severity of the phenotype ${ }^{2}$. The most common presenting feature is a coarsening of facial features, which becomes apparent between 2 and 4 years of age. The patients tend to have broad noses with flared nostrils, prominent supraorbital ridges, and large jowls. The lips may be thick, and they may have an enlarged protruding tongue. The head is of large circumference throughout life. Mobility is restricted because of joint stiffness and contractures. Patients with Hunter syndrome often walk on their toes because of joint stiffness and tight heel cords $2,3,6,7$.

The skeletal findings of Hunter syndrome, along with other MPS diseases, are collectively known as dysostosis multiplex, and most were described by Hunter in his original report ${ }^{2}$. Radiographic examination reveals abnormal thickness of all bones, and irregular epiphyseal ossification in the joints of the hand, shoulder, and elbow. Metacarpals and phalanges are abnormally short, wide and deformed with proximal pointing of metacarpals and bullet shaped phalanges. The ribs are thickened and have an unusual shape, and clavicles can be increased in bulk. The lateral surfaces of the vertebral bodies are irregularly notched in appearance ${ }^{2,3,6}$.

Other clinical features include frequent upper respiratory infections, sleep apnea, valvular heart disease leading to right and left ventricular hypertrophy and heart failure, chronic diarrhea, enlarged liver and spleen, umbilical as well as inguinal hernias,retinal degeneration (but no corneal clouding) with poor peripheral vision, progressive hearing loss caused by both conductive and sensorineural deficits. The common finding of moderate-to-severe communicating hydrocephalus may exacerbate the deterioration of the central nervous system ${ }^{2,3,5,6}$. The skin of patients with Hunter syndrome may be thickened and inelastic Patients with Hunter syndrome may have a distinctive skin lesion, which is described as ivory-white papules that are 2 to $10 \mathrm{~mm}$ in diameter ${ }^{2}$.

The initial suspicion of Hunter syndrome is often based on facial features and is made by the physician during an examination for other issues ${ }^{2}$. Analysis of urinary GAGs (heparan and dermatan sulphates) is the usual first screening test for MPS II, and can be quantitative (measurement of total urinary uronic acid) or qualitative (GAG electrophoresis) ${ }^{1}$. The presence of excess dermatan sulfate and heparan sulfate in urine is evidence that MPS I, MPS II, or MPS VII is present ${ }^{2}$. It is not diagnostic of Hunter syndrome, so additional tests must be performed. Definitive diagnosis is established by enzyme assay in leukocytes, fibroblasts or dried blood spots and plasma samples, using substrates specific for I2S ${ }^{1,8}$. Absent or low I2S activity in males is diagnostic of Hunter syndrome, provided that another sulfatase is measured and multiple sulphatase deficiency is ruled out ${ }^{1,2,3,8}$. Enzyme activity cannot be used to identify female carriers because, although on average I2S activity in female carriers is $50 \%$ of that seen in nonaffected individuals, considerable overlap exists ${ }^{2}$. Mutation analysis is necessary to confirm carrier status in females. Mutation analysis may be used to confirm Hunter syndrome in males. Gene analysis is the only secure way to identify female carriers and could be used for prenatal diagnosis, ${ }^{2}$ Prenatal diagnosis using amniocentesis and chorionic villus sampling can verify if a fetus either carries a copy of the defective gene or is affected with the disorder but this test is available in only a few laboratories worldwide ${ }^{6,9}$.

Until recently, the management of Hunter syndrome has been palliative and focused on the treatment of signs and symptoms ${ }^{2}$. Physical therapy and daily exercise may delay joint problems and improve the ability to move ${ }^{9}$. Enzyme replacement therapy using Idursulfase (Elaprase), a recombinant human $\mathrm{I} 2 \mathrm{~S}$ produced in a human cell line, has been recently approved in the United States and the European Union for the treatment of Hunter syndrome ${ }^{2}$. It is given by weekly intravenous infusion over $3 \mathrm{~h}$ at a dose of $0.5 \mathrm{mg} / \mathrm{kg}$ diluted in an appropriate volume of saline Patients may receive premedication with antipyretics and/or antihistamines at the discretion of the prescribing physician. Patients who have experienced infusion-related reactions should be pre-medicated for subsequent infusions ${ }^{1}$. Bone marrow transplantation (BMT) and umbilical cord blood transplantation (UCBT) have had limited success in treating the mucopolysaccharidoses ${ }^{6,9}$. 


\section{References}

1. J. Edmond Wraith, Maurizio Scarpa, Michael Beck, Olaf A. Bodamer, Linda De Meirleir, Nathalie Guffon, Allan Meldgaard Lund, Gunilla Malm, Ans T. Van der Ploeg and Jiri Zeman. Mucopolysaccharidosis Type II (Hunter Syndrome): A Clinical Review and Recommendations for Treatment in the Era of Enzyme Replacement Therapy. European J of Pediatrics 2008;167: 267277.

2. Rick Martin, Michael Beck, Christine Eng, Roberto Giugliani,, Paul Harmatz, Verónica Muñoz, and Joseph Muenzer, Recognition and Diagnosis of Mucopolysaccharidosis II (Hunter Syndrome) Review Article PEDIATRICS February 2008; Vol.121 No. $2: 377-386$

3. Kliegman RM, Behrman RE, Jenson HB, Stanton FB, Nelson text book of Pediatrics $18^{\text {th }}$ edtn Vol $1 ; 620-626$

4. Karin Tuschl, Andreas Gal, Eduard Paschke, Susanne Kircher and Olaf A. Bodamer. Mucopolysaccharidosis Type II in Females: Case Report and Review of Literature. Pediatric Neurology. April 2005; Vol 32:I 4:270-272.
5. Peining Li, Amy B Bellows, Jerry N Thompson. Molecular basis of iduronate-2-sulphatase gene mutations in patients with mucopolysaccharidosis type II (Hunter syndrome) J Med Genet January 1999;36:21-27

6. Publication of National Institute of Neurological Disorders and Stroke, National Institute of Health; Last updated Feb 072008.

7. R Froissart, I Moreira da silva, N Guffon, D Bozone I Maire; Acta Pediatrica, Suppliment 2002;439: 82-87

8. Caroline J. Dean, Michelle R. Bockmann, John J. Hopwood, Doug A. Brooks, Peter J. Meikle. Detection of Mucopolysaccharidosis Type II by Measurement of Iduronate-2- Sulfatase in Dried Blood Spots and Plasma Samples. Molecular Diagnostics and Genetics, Clinical Chemestry.2006;52:643-649

9. eMedicine; From Weikipedia, the free encyclopedia; Last updated Feb 26,2008 